\title{
KERAGAMAN DAN HERITABILITAS KETAHANAN TEBU POPULASI F TERHADAP PENYAKIT BERCAK KUNING DI PT GUNUNG MADU PLANTATIONS LAMPUNG
}

\author{
Nyimas Sa'diyah $^{1} \&$ Titik Nur Aeny ${ }^{2}$ \\ ${ }^{1}$ Bidang Budidaya Pertanian Jurusan Agroteknologi, Fakultas Pertanian, Universitas Lampung \\ ${ }^{2}$ Bidang Proteksi Tanaman Jurusan Agroteknologi, Fakultas Pertanian, Universitas Lampung \\ Jl. Prof. Soemantri Brojonegoro No.1 Bandar Lampung 35145, \\ E-mail:nyimas_diyah@yahoo.com
}

\begin{abstract}
Variability and heritability of $F_{1}$ sugarcane population resistance to yellow spot disease in PT. Gunung Madu Plantations Lampung. The objective of this study was to estimate variability and heritability of yellow spot disease characters of 12 sugarcane genotypes. The experiment was conducted on sugarcane field in PT Gunung Madu Plantations (PT GMP), Gunung Sugih Central Lampung, from January to May 2009. The treatments consisted of $12 \mathrm{~F}_{1}$ sugarcane genotypes resulted from the previous crossing of several existed varieties done by PT GMP research and development. The variability was estimated using the method from Anderson and Bancroft (1952) and the heritability was estimated based on the method from Allard (1995). The results showed that the severity of sugarcane yellow spot disease in the PT GMP Lampung showed high variability but low heritability (0.21). Out of 12 tested sugarcane genotypes, G12 has the highest resistance showed by the lowest disease severity.
\end{abstract}

Key words: sugarcane, yellow spot disease, resistance, variability, heritability

\section{ABSTRAK}

Keragaman dan heritabilitas ketahanan tebu populasi $F_{1}$ terhadap penyakit bercak kuning di PT. Gunung Madu Plantations Lampung. Penelitian ini bertujuan untuk menduga keragaman dan heritabilitas ketahanan 12 genotipe tebu terhadap penyakit bercak kuning. Percobaan dilaksanakan di lahan pertanaman tebu PT Gunung Madu Plantations (PT GMP), Gunung Batin, Lampung Tengah, dari Januari sampai dengan Mei 2009. Perlakuan terdiri atas populasi $\mathrm{F}_{1}$ dari 12 genotipe tanaman tebu hasil persilangan beberapa varietas tebu yang telah dilakukan oleh bagian R\&D PT GMP. Penilaian keragaman dilakukan berdasarkan metode Anderson dan Bancroft (1952) dan heritabilitas dihitung berdasarkan metode Allard (1995). Hasil penelitian menunjukkan bahwa keparahan penyakit bercak kuning pada tanaman tebu di PT GMP memilki keragaman yang luas dan heritabilitas yang tergolong sedang cenderung rendah $(0,21)$. Dari 12 genotipe tanaman tebu yang diuji, G12 memiliki tingkat ketahanan yang paling tinggi, ditunjukkan oleh tingkat keparahan penyakit bercak kuning yang paling rendah.

Kata kunci: tebu, penyakit bercak kuning, ketahanan, keragaman, heritabilitas

\section{PENDAHULUAN}

Produktivitas tanaman tebu merupakan hasil interaksi antara faktor internal tanaman dengan lingkungannya, dan salah satu faktor internal yang sangat menentukan produktivitas tersebut adalah varietas. Varietas berdasarkan sifat inherennya dapat direkayasa untuk menghasilkan tanaman yang dikondisikan unggul terhadap tujuan tertentu, misalnya tahan terhadap penyakit tertentu.

Penyakit-penyakit penting pada tanaman tebu yang terutama terdapat pada bagian daun antara lain adalah bercak kuning, karat, bercak cicin, bercak mata, luka api, dan leaf scroth (Rott et al., 2000; Semangun,
2000). Penyakit bercak kuning merupakan salah satu penyakit yang cukup penting pada tanaman tebu, meskipun pada awalnya tidak dianggap serius. Beberapa laporan tentang peledakan penyakit bercak kuning pada tanaman tebu dengan kehilangan hasil yang cukup besar di beberapa negara tropis penghasil tebu, menyebabkan penyakit bercak kuning saat ini dianggap sebagai penyakit bercak daun tebu yang paling penting di negaranegara tropis (Ricaud et al., 1980; Schubert \& Irey, 1986). Penyakit ini terutama banyak ditemukan pada tanaman tebu di dataran tinggi yang lembab. Di Philipina, penyakit bercak kuning merupakan salah satu penyakit yang paling penting dan menjadi ancaman yang serius pada tebu komersial karena tersebar sangat luas dan 
menyebabkan menghilangnya sebagian varietas lokal dan varietas asing terkenal dari beberapa perkebunan besar. Perkembangan penyakit tergantung pada kondisi cuaca terutama cuaca panas dan kelembapan yang tinggi. Selanjutnya Rott et al. (2000) juga menyatakan bahwa keberadaan penyakit noda kuning harus tetap diwaspadai karena penyakit ini pernah dilaporkan menimbulkan kerugian yang sangat signifikan di Australia, India dan Mauritius.

Penyakit noda kuning pada tanaman tebu menunjukkan gejala berupa bercak-bercak berwarna kuning pada permukaan daun-daun muda. Dengan berkembangnya daun, jumlah bercak akan bertambah dan beberapa bercak menyatu membentuk areal yang lebih luas dengan warna kemerah-merahan meliputi hampir seluruh daun (Irey \& Rice, 1986). Penyebab penyakit ini adalah cendawan Cercospora kopkei (Kruger) atau Mycovellosiela kopkei (Kruger) Deighton (Ricaud et al., 1980; Schubert \& Irey, 1986). Miselia cendawan ini pada umumnya keluar melalui stomata pada permukaan bawah daun, berwarna cokelat, dan bersekat. Penularan penyakit pada umumnya sangat dibantu oleh angin dan kondisi lingkungan yang lembab (Irey \& Rice, 1986; Semangun, 2000).

Penyakit bercak kuning pada tebu dilaporkan telah menimbulkan kerugian yang cukup besar karena menurunkan hasil panen sekaligus menurunkan kandungan gulanya. Pada tanaman yang terinfeksi berat, terutama pada fase pembungaan mengakibatkan penurunan kandungan gula dapat mencapai $23 \%$ (Ricaud et al., 1980). Autrey et al. (1983) menyatakan bahwa pada tingkatan infeksi tertentu tidak selalu mengakibatkan kehilangan hasil yang sama di suatu area yang berbeda. Ricaud \& Autrey (1989) mengemukakan bahwa kerusakan area daun yang mencapai $15 \%$ merupakan ambang terjadinya kehilangan hasil yang signifikan. Untuk mengurangi penurunan produksi tanaman akibat penyakit ini diperlukan strategi pengendalian yang efektif dan efisien. Pengendalian yang dapat dilakukan tidak hanya secara langsung yaitu melalui eradikasi, perlakuan air panas dan penggunaan pestisida saja tetapi juga harus didukung dengan cara pengendalian tidak langsung yaitu melalui penggunaan varietas tahan, penggunaan bibit sehat dan pengamatan dini (Ricaud et al., 1980). Pada kasus penyakit bercak kuning pada tebu, usaha untuk mengurangi penurunan produksi dan rendemen gula tanaman tebu, sangat dianjurkan untuk menggunakan varietas unggul yang tahan. Dalam Bureau of Agricultural Research (2009) dinyatakan bahwa salah satu cara pengendalian penyakit bercak kuning yang paling memuaskan adalah penggunaan varietas tahan. Sayangnya, varietas tebu yang tahan terhadap penyakit bercak kuning belum banyak tersedia karena berbagai keterbatasan.

Pembentukan varietas tebu unggul yang tahan terhadap suatu penyakit dapat dilakukan melalui program pemuliaaan, dan salah satu langkah pada program pemuliaan adalah seleksi. Untuk mendapatkan informasi tentang ketahanan varietas tebu terhadap penyakit bercak kuning, pada penelitian ini dilakukan seleksi terhadap 12 genotipe tebu populasi $\mathrm{F}_{1}$ yang merupakan hasil persilangan dari beberapa sumber tetua. Supaya seleksi yang dilakukan efektif maka perlu diperhatikan bagaimana keragaman dan heritabilitas karakter ketahanan terhadap penyakit bercak kuning pada tanaman tebu. Penelitian ini bertujuan untuk mengetahui keragaman dan heritabilitas karakter ketahanan tebu terhadap penyakit bercak kuning pada populasi $\mathrm{F}_{1}$ yang merupakan hasil persilangan antar beberapa varietas tebu yang ada di PT GMP Lampung Tengah.

\section{METODE PENELITIAN}

Tempat dan Waktu. Percobaan ini dilaksanakan di lahan pertanaman tebu PT Gunung Madu Plantations (PT GMP), Gunung Batin, Lampung Tengah, dari bulan Januari sampai dengan Mei 2009. Bahan percobaan adalah 12 genotipe tanaman tebu populasi $F_{1}$ yang merupakan hasil persilangan beberapa varietas tebu (Tabel 1) dengan umur tanaman sekitar enam bulan. Populasi $\mathrm{F}_{1}$ yang digunakan merupakan hasil persilangan yang dilakukan oleh peneliti dari bagian R\&D PT GMP. Persilangan dilakukan pada tetua-tetua yang memiliki waktu berbunga bersamaan. Oleh karena itu seleksi ketahanan dilakukan pada populasi $\mathrm{F}_{1}$. Informasi heritabilitas dapat digunakan untuk mengetahui apakah karakter ketahanan terhadap bercak penyakit kuning dipengaruhi oleh faktor genetik ataukah faktor lingkungan.

Bahan Percobaan. Bahan percobaan adalah 12 genotipe tanaman tebu populasi $\mathrm{F}_{1}$ yang merupakan hasil persilangan beberapa varietas tebu yang ada di PT GMP (Tabel 1) dengan umur tanaman sekitar enam bulan. Populasi $F_{1}$ yang digunakan tersebut merupakan hasil persilangan yang telah dilakukan sebelumnya oleh peneliti dari bagian R\&D PT GMP. Persilangan dilakukan pada tetua-tetua yang memiliki waktu berbunga bersamaan. Oleh karena itu seleksi ketahanan dilakukan pada populasi $\mathrm{F}_{1}$. Informasi tentang heritabilitas dapat digunakan untuk mengetahui apakah karakter 
ketahanan tanaman tebu terhadap penyakit bercak kuning dipengaruhi oleh faktor genetik ataukah faktor lingkungan.

Rancangan Percobaan. Perlakuan pada percobaan ini disusun dalam Rancangan Acak Lengkap (RAL), dengan 10 ulangan. Perlakuan berupa 12 genotipe tanaman tebu hasil persilangan beberapa varietas tebu (Tabel 1) dan unit ulangan berupa rumpun tanaman tebu.

$$
\begin{aligned}
\sigma_{f}^{2} & =\text { ragam fenotipe }=\text { ragam genotipe }+ \text { ragam } \\
& \text { lingkungan } \\
= & \sigma_{g}^{2}+\sigma_{e}^{2}=+\mathrm{M}_{1}
\end{aligned}
$$

Penilaian luas sempitnya keragaman dilakukan berdasarkan metode Anderson \& Bancroft (1952). Suatu karakter dikatakan memiliki keragaman yang luas

\begin{tabular}{|c|c|c|c|c|}
\hline No & Kode Genotipe & \multicolumn{3}{|c|}{ Persilangan antara } \\
\hline 1 & G1 & SS 57 & $\mathrm{X}$ & GM 23 \\
\hline 2 & G2 & SS 57 & $\mathrm{X}$ & RGM 99-15 \\
\hline 3 & G3 & SS 57 & $X$ & R GM 97-10167 \\
\hline 4 & G4 & RGM 99-5 15 & $X$ & GM 23 \\
\hline 5 & G5 & RGM 99-5 15 & $\mathrm{X}$ & IRV 93-2976 \\
\hline 6 & G6 & RGM 99-5 15 & $\mathrm{X}$ & R GM 2000-1050 \\
\hline 7 & G7 & RGM 99-5 15 & $X$ & GM 20 \\
\hline 8 & G8 & L $60-14$ & $\mathrm{X}$ & RGM 2000-1050 \\
\hline 9 & G9 & L $60-14$ & $\mathrm{X}$ & SS 113 \\
\hline 10 & G10 & L $60-14$ & $\mathrm{X}$ & GM 15 \\
\hline 11 & G11 & L 60-14 & $\mathrm{X}$ & GM 23 \\
\hline 12 & G12 & L $60-14$ & $\mathrm{X}$ & X3 \\
\hline
\end{tabular}
apabila nilai ragamnya lebih besar dari dua kali nilai

Tabel 1. Daftar 12 genotipe tanaman tebu hasil persilangan, yang digunakan dalam penelitian

Pengamatan. Pengamatan gejala penyakit dilakukan setiap hari terhadap tanaman dalam setiap rumpun yang daunnya menunjukkan gejala penyakit bercak kuning. Pada masing-masing genotipe, tingkat keparahan penyakit dihitung dalam persen. Nilai keparahan penyakit diperoleh dengan cara menginterpretasikan berapa persen proporsi bercak yang ada pada setiap daun pada setiap tanaman yang diamati. Selanjutnya data keparahan penyakit bercak kuning dianalisis dengan menggunakan sidik ragam (Tabel 2). Berdasar Tabel 2, dapat dihitung ragam genotipe $\left(\sigma_{g}^{2}\right)$ dan ragam fenotipe $\left(\sigma_{f}^{2}\right)$ dengan rumus sebagai berikut:

$\sigma_{g}^{2}=$ ragam genotipe $=\frac{M_{2}-M_{1}}{\text { ulangan }}$ simpangan bakunya. Sebaliknya, keragaman dikatakan sempit apabila nilai ragam lebih kecil dari dua kali nilai simpangan bakunya.

Simpangan baku ragam genotipe ditentukan berdasarkan rumus dari Halluer \& Miranda (1988), yaitu:

$$
\begin{aligned}
& \sigma_{\sigma_{g}^{2}}=\sqrt{\frac{2}{r^{2}}\left[\frac{M_{2}{ }^{2}}{\text { dbgenotipe }+2}+\frac{M^{2}}{\text { dbgalat }+2}\right.} \\
& \sigma_{\sigma_{g}^{2}}=\sqrt{\frac{2}{r^{2}}\left[\frac{M_{2}{ }^{2}}{\text { dbgenotipe }+2}\right.}
\end{aligned}
$$

Tabel 2. Sidik ragam keparahan penyakit bercak kuning tebu

\begin{tabular}{ccccc}
\hline $\begin{array}{c}\text { Sumber } \\
\text { keragaman }\end{array}$ & $\mathrm{db}$ & $\mathrm{JK}$ & $\begin{array}{c}\text { Kuadrat Nilai } \\
\text { Tengah }\end{array}$ & $\begin{array}{c}\text { Kuadrat Nilai } \\
\text { Tengah Harapan }\end{array}$ \\
\hline Genotipe & $\mathrm{g}-1$ & JK genotipe & $\mathrm{M} 2$ & $\sigma_{e}^{2}+\mathrm{r} \sigma_{g}^{2}$ \\
Galat & $\mathrm{g}(\mathrm{r}-1)$ & JK galat & $\mathrm{M} 1$ & $\sigma_{e}^{2}$ \\
\hline
\end{tabular}


Heritabilitas dihitung berdasarkan metode atau rumus yang dikemukakan oleh Allard (1995) yaitu:

$$
\mathrm{H}=\frac{\sigma_{g}^{2}}{\sigma_{f}^{2}}
$$

Klasifikasi heritabilitas berdasarkan Mc.Whirter (1979) adalah sebagai berkut. Heritabilitas tinggi apabila nilai $\mathrm{H}>0,5$; heritabilitas sedang apabila nilai $0,2 \leq \mathrm{H} \leq 0,5$; eriabilitas rendah apabila nilai $\mathrm{H}<0,2$.

Sebaran data keparahan penyakit bercak kuning dilihat dengan menggunakan median dan kisaran (range) antara kwartil 1 dan kwartil 3 serta boxplot. Perhitungan boxplot dilakukan dengan menggunakan Minitab versi 14.

\section{HASIL DAN PEMBAHASAN}

Keragaman Genotipe dan Fenotipe Keparahan Penyakit Bercak Kuning. Berdasarkan kriteria yang dikemukakan oleh Anderson \& Bancroft (1952), diketahui bahwa keragaman genotipe dan fenotipe untuk ketahanan terhadap penyakit bercak kuning dari 12 genotipe hasil persilangan beberapa varietas tebu di PT Gunung Madu Plantations yang diuji pada penelitian ini cukup luas (Tabel 3 ). Keragaman yang luas ini, diduga disebabkan oleh sumber tetua yang beragam yaitu meliputi SS, GM, RGM, IRV, L, dan X yang mungkin saja memiliki ketahanan terhadap bercak kuning yang beragam pula. Keragaman genetik yang berbeda antar varietas ini diduga disebabkan oleh kekerabatan yang luas karena asalnya yang berbeda. Misalnya, tetua SS 57 telah dilaporkan bersifat sangat rentan terhadap penyakit bercak kuning (PT GMP Research and Development, 2007).

Keragaman keparahan penyakit bercak kuning pada penelitian ini memiliki median berkisar antara 1,25\% (G11) sampai 17\% (G2), tetapi masing-masing genotipe hasil persilangan memiliki kisaran keparahan penyakit bercak kuning yang beragam (Gambar 1). Pada G8, keparahan penyakitnya berkisar pada $0-26,25 \%$ dengan median $2,1 \%$ serta kuartil $1=0 \%$ dan kuartil $3=9,16 \%$, sedangkan kisaran keparahan penyakit bercak kuning

Tabel 3. Keragaman genotipe dan fenotipe keparahan penyakit bercak kuning pada 12 genotipe hasil persilangan beberapa varietas tebu PT GMP

\begin{tabular}{lcccccc}
\hline Karakter & $\begin{array}{c}\text { Ragam } \\
\text { genotipe }\end{array}$ & $2\left(\sigma_{\sigma_{g}^{2}}\right)$ & Kriteria & $\begin{array}{c}\text { Ragam } \\
\text { fenotipe }\end{array}$ & $2\left(\sigma_{\sigma_{f}^{2}}\right)$ & Kriteria \\
\hline $\begin{array}{l}\text { Keparahan } \\
\text { penyakit } \\
\text { bercak kuning }\end{array}$ & 12,28 & 10,1 & luas & 56,00 & 10,04 & luas \\
\hline
\end{tabular}

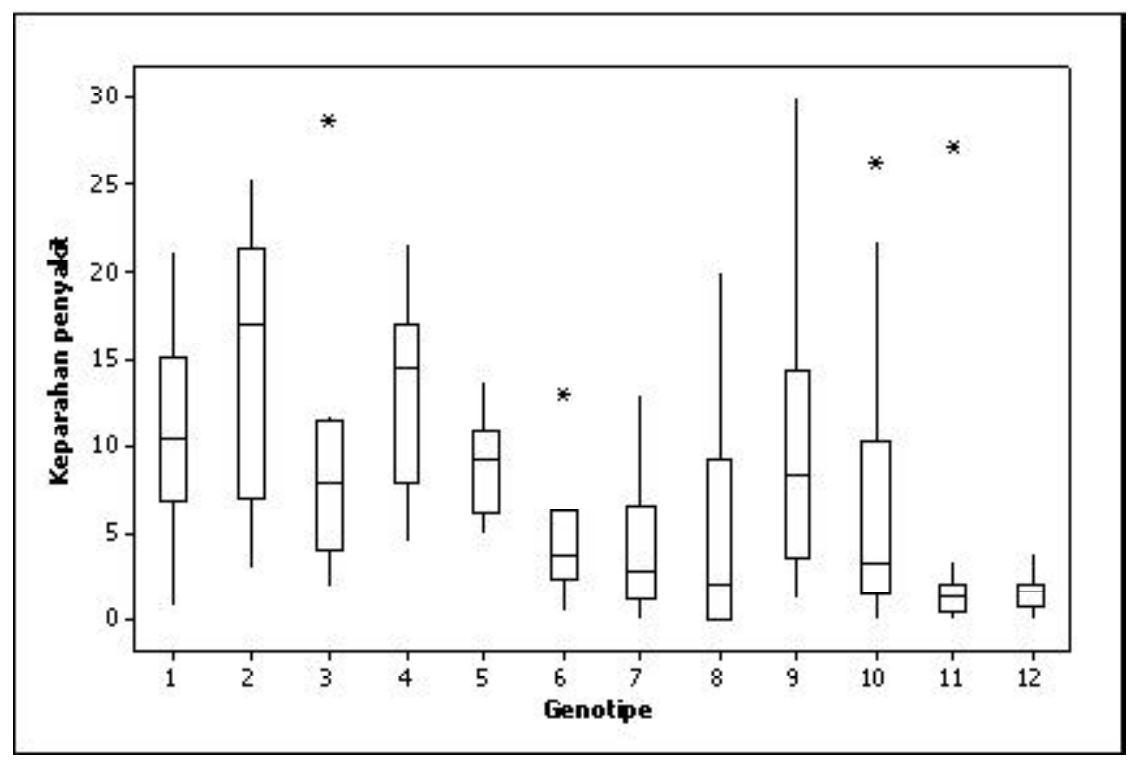

Gambar 1. Sebaran keparahan penyakit bercak kuning pada 12 genotipe hasil persilangan beberapa varietas tebu PT. GMP Lampung. 
yang paling rendah terdapat pada G12, yaitu $0-3,8 \%$ dengan median $1,68 \%$ serta kuartil $1=0,78 \%$, kuartil 3 $=2,08 \%$ dan memiliki data pencilan dengan keparahan penyakit 3,8\%. Dari 12 genotipe yang diuji terdapat empat genotipe yang memiliki data pencilan yaitu G3, G6, G11, dan G12. Data pencilan ini yang diduga menyebabkan rata-rata menjadi bias (Tabel 4).

Keragaman ketahanan tanaman tebu terhadap penyakit bercak kuning yang luas akan memberi peluang cukup baik bagi pemulia tanaman untuk memilih dan mendapatkan varietas yang lebih tahan karena pemulia tanaman memiliki keleluasan dalam memilih varietas yang diinginkan. Hal ini sejalan dengan hasil penelitian Abdelmahmoud dkk. (2009) dan Hakim (2010) yang menyatakan bahwa seleksi akan efektif apabila tanaman mempunyai keragaman suatu karakter yang luas. Dari 12 genotipe yang diuji, G12 memiliki tingkat ketahanan yang paling tinggi, ditunjukkan dengan tingkat keparahan penyakit bercak kuning yang paling rendah (Gambar 1, Tabel 4). Genotipe G12, yang merupakan hasil persilangan antara tetua L60-14 dengan X3, mempunyai keparahan penyakit yang paling rendah diantara genotipe-genotipe lain yang berasal dari hasil persilangan antara tetua L60-14 dengan pasangan tetua yang lain. Dengan demikian dapat diduga bahwa sifat ketahanan yang dimiliki oleh genotipe G12 lebih ditentukan oleh tetua X3.

Efektifitas seleksi tidak hanya ditentukan oleh keragaman genetik dan fenotipik yang luas tetapi juga oleh ketentuan apakah karakter tersebut diturunkan atau tidak. Oleh karena itu, perlu dilihat nilai duga heritabilitasnya. Karena perhitungan nilai duga heritabilitas ini hanya dilakukan pada sekali tanam maka nilai duga heritabilitas yang dihitung adalah heritabilitas dalam arti luas (H). Heritabilitas dalam arti luas merupakan perbandingan total ragam genetik terhadap ragam fenotipenya, sedangkan total ragam genetik itu sendiri meliputi ragam aditif, ragam dominan dan ragam epistasi. Dari hasil penelitian ini diketahui bahwa keparahan penyakit bercak kuning pada tanaman tebu di PT GMP Lampung memilki heritabilitas dalam arti luas $(\mathrm{H})$ sebesar 0,21 atau tergolong sedang cenderung rendah.

Poelman \& Borthakur (1972) melaporkan bahwa tanaman tebu termasuk tanaman yang banyak dikembangkan secara vegetatif, dan proses untuk mendapatkan klon unggul diperlukan waktu yang lama yaitu sampai dengan sepuluh musim tanam. Meskipun perbanyakan tanaman tebu dilakukan secara vegetatif, secara genetik keturunan yang dihasilkan masih sama dengan tetuanya. Hanya saja, faktor lingkungan pada sepuluh kali musim tanam akan tetap mempunyai pengaruh terhadap fenotipe yang dihasilkan. Dengan demikian, nilai duga heritabilitas pada tanaman yang diperbanyak secara vegetatif masih tetap diperlukan untuk melihat seberapa besar pengaruh lingkungan terhadap keragaman fenotipik suatu karakter. Hal ini sejalan dengan hasil penelitian Wahyuni dkk. (2004). Dari hasil penelitian ini diketahui bahwa hampir semua genotipe tanaman tebu yang diuji mempunyai keragaman genotipe dan fenotipe yang luas, sedangkan nilai heritabilitas dalam arti luasnya $(\mathrm{H})$ sedang cenderung rendah. Hal ini menunjukkan bahwa karakter ketahanan ini terjadi cenderung lebih dipengaruhi oleh faktor

Tabel 4. Data keparahan penyakit terendah, tertinggi, rata-rata, median, kuartil 1, dan kuartil 3 dari 12 genotipe yang diuji

\begin{tabular}{cccrrrr}
\hline Genotipe & $\begin{array}{c}\text { Data } \\
\text { terendah }\end{array}$ & $\begin{array}{c}\text { Data } \\
\text { tertinggi }\end{array}$ & Rata-rata & Median & Kuartil 1 & Kuartil 3 \\
\hline G1 & 0,80 & 21,20 & 10,73 & 10,40 & 6,85 & 15,10 \\
G2 & 3,00 & 25,40 & 14,97 & 17,00 & 7,00 & 21,33 \\
G3 & 2,00 & 28,75 & 9,28 & 7,95 & 3,84 & 11,55 \\
G4 & 4,46 & 21,66 & 13,03 & 14,50 & 7,83 & 16,98 \\
G5 & 12,20 & 9,37 & 9,06 & 9,29 & 6,03 & 10,93 \\
G6 & 0,40 & 13,00 & 4,46 & 3,72 & 2,35 & 6,17 \\
G7 & 0,00 & 13,00 & 4,23 & 2,80 & 1,19 & 6,68 \\
G8 & 0,00 & 20,00 & 5,38 & 2,10 & 0,00 & 9,16 \\
G9 & 1,20 & 30,00 & 10,36 & 8,25 & 3,50 & 14,40 \\
G10 & 0,00 & 26,25 & 7,07 & 3,35 & 1,53 & 10,25 \\
G11 & 0,00 & 27,10 & 3,78 & 1,25 & 0,45 & 2,05 \\
G12 & 0,00 & 3,80 & 1,56 & 1,68 & 0,78 & 2,08 \\
\hline
\end{tabular}


lingkungan dibandingkan faktor genetik (Chaudary, 2000/ 2001; Suharsono dkk., 2006; Suprapto dkk., 2007).

\section{SIMPULAN}

Secara umum dapat disimpulkan bahwa keparahan penyakit pada tanaman tebu populasi $\mathrm{F}_{1}$ hasil persilangan antar beberapa tetua yang diuji di lahan perkebunan PT GMP mempunyai keragaman yang luas dan heritabilitas yang tergolong sedang cenderung rendah $(0,21)$. Dari 12 genotipe tebu yang diuji, G12 memiliki tingkat keparahan penyakit bercak kuning yang paling rendah atau tingkat ketahanan tanaman yang paling tinggi.

\section{SANWACANA}

Penulis menyampaikan terima kasih kepada manajemen PT Gunung Madu Plantation Lampung yang telah memberi ijin dan menyediakan lahan beserta tanaman tebu untuk penelitian ini. Ucapan terima kasih yang tulus juga penulis sampaikan kepada Bapak Ir. Remaja Sitepu dan Sdri. Sefti Irawati, S.P. yang telah membantu selama pelaksanaan penelitian ini.

\section{DAFTAR PUSTAKA}

Abdelmahmoud, Ahmed O, Vijayakumar G, Natrajan US, \& Babu C. 2009. Variability for cane yield and quality characters among full-sib progenies of sugarcane (Saccharum spp.) on family basis. Electronic Journal of Plant Breeding 1:37-42

Allard RW. 1995. Pemuliaan Tanaman. Diterjemahkan oleh Manna. Diedit oleh Mulyani M. Rineka Cipta. Jakarta.

Anderson RL \& Bancroft TA. 1952. Statistical Theory in Research. McGraw-Hill Book Inc. New York.

Autrey LJC, Ricaud C, Sullivan S \& Dhayan S. 1983. Control of yellow spot disease of sugarcane by aerial application of fungicide. Sugar Azucar 78(7):23-25.

Bureau of Agricultural Research. 2009. Yellow spot, Mycovellosiela kopkei Kruger. http:// www.bar.gov.ph/biofuelsinfo/bioethanol/ sugarcanep\&d/yellowspot.asp. Diakses pada 17 Maret 2011.

Chaudary RR. 2000/2001. Genetik variability dan heritability in sugarcane. Nepal Agric. Res. J. Vol 4 \& 5: 56-59.
Direktorat Jenderal Hortikultura Departemen Pertanian. 2009. Volume eksport komoditas sayuran di Indonesia periode 2003-2008. www. Hortikultura.deptan.go.id (diperbaharui 17 Maret 2011)

Hakim L. 2010. Keragaman genetik, heritabilitas dan korelasi beberapa karakter agronomi pada galur $\mathrm{F}_{2}$ hasil persilangan kacang hijau (Vigna radiata (L.) Wilezek). Berita Biologi 10(1); 23-32.

Hallauer AR \& Miranda JB. 1988. Quantitative Genetics in Maize Breeding. $1^{\text {st }}$ Ed. Iowa State Univ. Press/Ames.

Irey MS \& Rice ER. 1986. First report of yellow spot disease of sugarcane in the United States. Sugar Journal 48(9):11-12.

Kristini A, Achdian EM, Irawan, Putra LK, Pratiwi TD, Mulyadi M \& Muwardono. 2009. Potret Penyakit Tebu di Jawa: Distribusi dan Dominasi Penyakitpenyakit Tebu Penting. MPG Vol. 44: $205-218$.

McWhirter KS. 1979. Breeding of cross pollinated crops. Pp: 79-88. In R. Knight (ed). Plant Breeding. A.A.U.C.S., Brisbane.

Poelman JM \& Borthakur D. 1972. Breeding Asian Field Crops. Oxford \& IBH Publishing Co. New Delhi.

Ricaud C, Autrey LJC \& Sullivan S. 1980. Losses from the recurrence of yellow spot epiphytotics in Mauritius. Sugar Azucar 75(7):28-39.

Ricaud C \& Autrey LJC. 1989. Yellow Spot. Pp. 231245. In: Ricaud C, Egan BT, Gillaspie, AG Jr \& Hughes CG (Eds.). Diseases of Sugarcane: major disease. Elsevier, Amsterdam.

Rott P, Balley RA, Comstock JC, Croft BJ, \& Saumtally AS (Eds.). 2000. A Guide to Sugarcane Diseases. CIRAD \& ISSTCT.

Schubert TS \& Irey MS. 1986. Yellow Spot Disease of Sugarcane. Plant Pathology Circular No. 289 November 1986.

Semangun H. 2000. Penyakit - Penyakit Tanaman Perkebunan di Indonesia. Gadjah Mada University Press. Yogyakarta.

Suharsono, Yusuf M \& Paserang AP. 2006. Analisis ragam, heritabilitas dan pendugaan kemajuan seleksi populasi F2 dari persilangan kedelai kultivar Slamet x Nokonsawon. Tanaman Tropika 9(2): 86-93. 
Suprapto \& Khairudin NM. 2007. Variasi genetik, heritabilitas, tindak gen dan kemajuan genetik kedelai (Glycine max Merril) pada Ultisol. Jurnal Ilmu-Ilmu Pertanian Indonesia 9(2):183-190.
Wahyuni TS, Setiamihardja R, Hermiati N \& Hendroatmodjo KH. 2004. Variabilitas genetik, heritabilitas, dan hubungan antara hasil umbi dengan beberapa karakter kuantitatif dari 52 genotip ubijalar di Kendalpayak, Malang. Zuriat 15 (2):109-117. 